\title{
Correction to: Hydraulic fracture propagation and interaction with natural fractures by coupled hydro-mechanical modeling
}

\author{
Yu Hu $\cdot$ Quan Gan (D) Andrew Hurst - Derek Elsworth
}

Published online: 21 December 2021

(C) Springer Nature Switzerland AG 2021

Correction to: Geomech. Geophys. Geo-energ.

Geo-resour. (2022) 8:4

https://doi.org/10.1007/s40948-021-00307-9

In the original publication of the article, the affiliation of the first author was published incorrectly. The correct affiliation is given in this Correction. The original article has been corrected.

The original article can be found online at https:// doi.org/10.1007/s40948-021-00307-9.

Y. Hu $\cdot$ Q. Gan $(\varangle) \cdot$ A. Hurst

Department of Geology and Geophysics, School of Geosciences, University of Aberdeen, Aberdeen, UK e-mail: quan.gan@cqu.edu.cn

$\mathrm{Y} . \mathrm{Hu}$

CNOOC Research Institute, Beijing, China

Q. Gan

College of Resources and Safety Engineering, Chongqing

University, Chongqing, China

D. Elsworth

Department of Energy and Mineral Engineering, EMS

Energy Institute and G3 Center, Pennsylvania State

University, University Park, Pennsylvania, USA
$\mathrm{Yu} \mathrm{Hu}$

1. Department of Geology and Geophysics, School of Geosciences, University of Aberdeen, UK

2. CNOOC Research Institute, Beijing, China

Publisher's Note Springer Nature remains neutral with regard to jurisdictional claims in published maps and institutional affiliations. 